\title{
Sponsorship of nutrition research in developing countries
}

\author{
Hester Vorster* \\ Faculty of Health Sciences, Private Bag X 6001, Lipid Clinic, PU for CHE, Potchefstroom 2520, South Africa
}

The paper in this issue by Nestle ${ }^{1}$ is a timely reminder of the ethical issues surrounding the funding of nutritional scientific activities. She concludes that, in an ideal world, no nutritionist would need funding from the food industry, but given the present reality, the challenge is to recognise and minimise potential conflicts and to keep public health interest at the forefront of professional actions and opinions.

But how do we minimise the risk of being influenced by sponsors, even when that influence is unintentional? How do we equip young scientists to practice science and not advertising? Some of the measures Nestle ${ }^{1}$ quotes, for example the disclosure of competing interests required by the British Medical Journal, may in themselves be biased, undemocratic, and in South Africa at least, unconstitutional. Perhaps one should look at the problem, together with the current reality, through an Einsteinian lens of relativity; by accepting that there is no absolute truth and that people will see and experience reality relative to their own positions; and by trying to create a win-win situation, without too much compromise, from these different viewpoints.

There are five major positions from which the issue of industry sponsorship of scientific and professional nutrition activities can be regarded: the industry, the academic, the professional and scientific society, the nutrition and related journals, and the consumer. The consumer has the right to make an informed choice, based on scientific evidence or on responsible advertising. Nestle ${ }^{1}$ urges the nutrition journals to introduce measures similar to those adopted by some medical journals. Many professional and scientific societies are concerned about funding issues. For example, the International Union of Nutritional Sciences has very specific guidelines for accepting sponsorship for scientific events. I would therefore like to concentrate on the relationship between industry and the academic researcher.

The food industry provides an invaluable service to consumers by marketing safe, and mostly nutritious foods and food products. It realises that many of today's consumers are both nutrition-wise and conscious, and it therefore uses nutrition messages and development of novel foods to obtain market force, often through employment of nutritionists, dieticians and food scientists. There are many examples where competition within the food industry has benefited consumers, such as the marketing and availability of high fibre, low fat and micronutrient-enriched products, but there are also many examples - mentioned by Nestle $^{1}$ - where subjective interpretations of research results, nutrition advertising and promotion by industry result in conflicting, inaccurate and sometimes irresponsible messages to the consumer. This is ultimately driven by the need for industry to make money for its shareholders, and therein lies the pitfalls that academic researchers are exposed to, so aptly described by Nestle ${ }^{1}$.

There is, however, another danger for the academic researcher to be aware of. Not only is there the possibility of subjective interpretation and conclusion of research funded by industry, but there is also the problem of choice to be addressed. Many researchers have learnt that, to be successful in research grant applications, a win-win situation must be created by accommodating both the sponsor's and one's own research agenda. The research area, focus, questions, aims, objectives or expected outcomes are often formulated by the funding organisation, resulting in academic research being driven or guided by pragmatic considerations - applied to solve perceived or real public health problems or to generate information and collect evidence that can be used by the funder for its own financial or political benefit. Therefore, totally objective, creative and innovative research is rarely funded under such a system. In South Africa, and probably in most developing countries, funding for basic research is limited because there are so many other budgetary constraints. Therefore, reliance on sponsorship by food and pharmaceutical industries may be even greater than in the developed world. Many deserving projects and programmes in the developing world have been funded by United Nations Agencies, and although these have produced results that benefited developing populations, this funding has probably guided research to the extent that individual researchers could not follow their own, creative initiatives.

A possible solution to the problem is to create an independent nutrition-funding agency, foundation or trust, acting at global, regional or national scales. Industry could or should donate funds to this foundation or trust from their research and not their advertising budgets without dictating or knowing which research projects are 
being sponsored with their money. Such a foundation or trust should be administered by a scientific panel, and researchers should not know which industry is funding them. This set-up should remove possible bias and subjective interpretation of results. It will also stimulate creative and innovative research agendas.

Creating an independent structure will require enormous trust by industry in the nutrition research community. It may sound idealistic, even naive, but it would be in the interest of industry to use research results to develop and market products based on science that is totally objective and above suspicion. The history of nutrition research has shown that industry can be assured of eventual benefits. Much of the knowledge used today in producing and marketing foods and food products has been gained by innovative and original research not originally funded by industry. For example, the knowledge that high fibre diets protect against chronic noncommunicable disease was applied in the marketing of numerous high fibre foods such as breakfast cereals, benefited millions, and originated through research and observations by researchers in Africa not sponsored by the industry. The food industry owes a debt to nutrition research, and by paying this debt through an independent structure, will itself benefit.

I share the concerns expressed by Nestle ${ }^{1}$, although I do not agree with all her suggestions to minimise risk. We owe it to the next generation of nutrition researchers to go further in ensuring adequate and appropriate funding, to enable them to follow their own unbiased research agendas, and for producing credible results that can be applied for the benefit of mankind.

\section{Disclosure}

My full salary is paid by the Potchefstroom University for Christian Higher Education. Most of my research is funded by the South African (SA) National Research Foundation and the SA Medical Research Council. However, I have accepted funding from the food industry.

I have never hesitated to accept funding for our Lipid Clinic from the SA Dried Bean Producers Organisation because I believe that all South Africans, rich or poor, under- or over-nourished, can benefit by consuming more legumes.

I have also accepted funding from the SA Egg Board to examine the influence of egg consumption on the risk of developing coronary heart disease. This funding was motivated by earlier research and our suspicion that it was unethical to advise poor, nutritionally compromised people to limit egg intake based on its cholesterol content. Eggs are an affordable source of high quality protein for many South Africans.

I have also received grants from the South African Sugar Association for the empirical work of several Masters and Doctoral Students in Physiology, Sports Nutrition, Community Nutrition and Dietetics. All fees for consultancy and contract research done by my group for the food industry have been used for student grants or funding of other research projects.

\section{References}

1 Nestle M. Food company sponsorship of nutrition research and professional activities: a conflict of interest? Public Health Nutr. 2001; 4: 1015-22. 